\title{
RAVIZZA, Padre João. Gramática latina. Rio de Janeiro: Editora CDB, 2020. 716 p. ISBN: 978-65-89415-01-5
}

\author{
Paulo Sérgio de Vasconcellos*
}

Recebido em: 18/03/2021

Aprovado em: 14/06/2021

$\mathrm{P}$

or que resenhar em 2021 uma obra de perfil escolar que, em sua primeira edição, tem mais de oitenta anos? Não o fazemos apenas porque ela foi reeditada recentemente, mas - e sobretudo - porque lhe acrescentaram, nessa reedição recente, uma apresentação cujo conteúdo traz à baila uma grave questão de que os classicistas brasileiros devem se ocupar com urgência. Logo chegaremos a esse ponto.

Em prefácio do autor datado de 1940 (mas não incluído nesta reedição), explicita-se a preocupação didática da obra, destinada aos estágios na antiga escola que precedem a universidade:

Destina-se esta gramática aos estudantes dos cursos ginasiais e complementares ou pré-universitários. Por ser a mais extensa e completa até agora publicada em língua portuguesa, é a melhor para ser adotada nos Seminários em que o curso de latim deve ser feito em seis anos. ${ }^{1}$

João Ravizza (1885-1941), um sacerdote milanês da ordem dos salesianos, residiu por muitos anos no Brasil, onde, entre outras atividades, foi professor de latim por dezoito anos em Lorena, no interior de São Paulo. Sua gramática latina é um extenso manual que tem declaradamente a intenção de completude, expressa no prefácio já citado; o apresentador da edição que resenhamos afirma tratar-se de "o mais completo e abrangente manual de gramática latina já publicado em língua portuguesa” (2020, p. 15), o que parece verdadeiro.

${ }^{1}$ Disponível em https://latim.paginas.ufsc.br/files/2012/06/Gram\% C3\%A1tica-Latina.-Ravizza.pdf (p. 5). (Itálicos do original.) 
Como era previsível, a gramática de Ravizza tem um perfil tradicional, apresentando a seguinte divisão em partes: Fonologia; Morfologia; Sintaxe (a mais extensa). Seguem-se onze "apêndices": Origem e difusão da língua latina; Distinção entre o latim clássico e o latim vulgar; Calendário romano; Prosódia e métrica; Pequenas notas filológicas sobre as declinações do verbo latino; Abreviaturas epigráficas; Moedas, pesos e medidas dos romanos; Dos nomes próprios dos romanos; Alguns nomes de ortografia notável; Pronúncia romana do latim; Compêndio da história da literatura latina (escrito por João Masera). Os apêndices somam mais de duzentas páginas do conjunto nesta reedição.

A feição normativa da obra se revela no apêndice "Alguns nomes de ortografia notável". O autor recomenda não grafar, por exemplo, aethereus, mas, sim, aetherius; belua, não bellua (2020, p. 597) etc; as grafias reprovadas, porém, encontram-se registradas no Oxford Latin Dictionary - e o mesmo se poderia dizer a respeito de outras grafias arroladas e desaconselhadas. Todo esse apêndice prestará hoje um desserviço se estiver desacompanhado das advertências de um especialista que chame a atenção para o quanto há de datado ou ao menos impreciso aqui. Observemos que há na presente reedição um erro tipográfico que não encontramos em outra edição que possuímos: o perfeito de reperio é dado como "repperri", mas o autor dizia originalmente o correto repperi.

O apêndice que traz um compêndio da literatura latina (não escrito por Ravizza, como apontamos) tem não pouco material datado, como é compreensível. Veja-se o que se diz sobre Propércio:

O amor é elemento dominante da sua natureza: abandona-se ao sentimentalismo mesmo onde o amor o não exige, e disto podemos talvez encontrar a razão na sua fraca saúde, de que faz frequentes acenos (2020, p. 658).

Este é um exemplo claro de "biografismo": atribui-se um suposto aspecto da obra a uma condição física do autor de carne e osso de uma maneira ingênua, mas é claro que fazemos essa observação do ponto de vista de alguém que fala oitenta anos depois, influenciado por um tipo de interpretação cujo predomínio nos Estudos Clássicos é relativamente recente. Vale o mesmo tipo de ressalva quando apontamos o caráter datado do procedimento de chamar a "Idade de Cícero e Augusto" de "idade áurea da literatura latina, tanto pela forma como pela substância” (2020, p. 633), fruto de uma concepção evolucionista da literatura hoje desprestigiada no meio acadêmico. Ao tratar do poema de Lucrécio, na p. 645, temos: "Diz-se que Cícero corrigiu esse poema, mas se isto fosse verdade, Cícero não teria deixado de fazer menção, ao passo que raramente menciona a Lucrécio, e embora admitindo que é homem de talento, o julga de cultura artística deficiente" (grifo nosso). Aqui parece ter havido incompreensão do julgamento de Cícero a respeito do poema, expresso numa carta a seu irmão Quinto (II, 9,3) e em que o orador elogia não apenas o talento natural (ingenium) como também a arte (ars) de Lucrécio: Lucreti poemata ut scribis ita sunt, multis luminibus ingeni, multae tamen artis. Essa é a lição dos manuscritos; se não se pode excluir que o autor do comentário tenha lido alguma versão corrigida da frase (cujo tamen provoca discussão), deveria, porém, 
ter assinalado isso. Fato é que todos os autores que pudemos consultar interpretam-na no sentido de um elogio de Cícero ao ingenium e à ars de Lucrécio.

Um problema dos manuais é a superficialidade, e aqui e ali podemos perceber como isso se traduz em informação ao menos imprecisa. Ao tratar de Catulo no apêndice, Masera diz: "Nasceu em Verona em 87 a.C. e morreu com pouco mais de 30 anos". Há uma complexa discussão sobre a data de nascimento de Catulo e o número de anos que viveu, sempre a partir de célebre informação de São Jerônimo, confrontada com dados da obra do poeta, mas o manual apresenta a questão como se ela não suscitasse nenhuma controvérsia. Pensamos que um editor especialista poderia chamar a atenção do leitor moderno para tais passagens.

Alguns pequenos erros de estampa que encontramos nessa parte: na p. 618, grafa-se "Amphiturno" o que é Amphitruo. Mas esse erro vem de edições anteriores. Na p. 620, temos "Tragaediae", em vez de Tragoediae, grafia correta de outras edições dessa gramática. Na p. 640, temos a obra de Cícero grafada como “De optimo genere oratorem”, mas se deveria grafar oratorum, e esse erro também não constava de edições anteriores, ao que pudemos avaliar.

Vemos um problema mais sério no breve apanhado dedicado à pronúncia do latim. Essa seção (p. 24-6) provocará grande confusão no leitor que estudar a pronúncia da língua apenas guiado pela gramática de Ravizza. Na observação 1) da p. 25, diz-se "Os ditongos ae e oe pronunciam-se como e, p. ex.: aetas, poena = etas, pena". Obviamente, essa não é a pronúncia dita clássica ou "restaurada"; mas ao tratar das consoantes, coloca-se "c" e "g", entre as guturais, junto com "k": essa, porém, é a pronúncia clássica tal como reconstituída pelos especialistas. Há, então, informações que confundem pronúncia "romana” e pronúncia "reconstituída". Não há, de resto, nessa subseção intitulada "Sons", exemplos, nem qualquer tipo de confronto didático com sons do português. Assim, nessa parte da gramática, aquele ideal de completude expresso pelo autor não se concretiza. Em suma, as observações dessa seção não têm, praticamente, valor didático; sobretudo, seria preciso advertir os alunos sobre as várias pronúncias do latim e adequar todas as informações de acordo com a pronúncia que se está ensinando nessa parte da gramática. Nitidamente, vê-se que não se pensa no leitor autodidata, mas no aluno que consultará o material amparado pelas observações de um professor em sala de aula, o que não invalida, a nosso ver, os reparos que fazemos. Por fim, é significativo que no apêndice VIII (p. 605-7) se apresente a pronúncia romana, da tradição católica, com os detalhes e o didatismo que não vemos na exposição do que seria a pronúncia clássica reconstituída.

Em resumo, sobre a reedição da gramática em si, que tem projeto gráfico muito bom e, pela amostragem que analisamos, poucas gralhas (algumas grafias incorretas, falta de itálico), julgamos que se perdeu uma oportunidade de apresentar esse material didático com o devido "aggiornamento". Os italianos têm a tradição de reeditar estudos do passado ainda relevantes acompanhados de notas e comentários, por vezes exaustivos, a respeito de determinado ponto, atualizando a bibliografia e colocando em perspectiva o que vai dito no original reeditado. A reedição da gramática de Ravizza poderia ter sido feita nesses termos. Uma edição "aggiornata" à moda italiana justificaria melhor a reedição de um livro que pode ser útil para consulta dos alunos de graduação das nossas universidades e do leitor autodidata 
(que, porém, não tem aqui um método para aprender a língua, mas um panorama amplo, para consulta, de seus principais usos na literatura clássica). Mas deixamos para o final o que nos parece o maior problema desta edição: a apresentação que lhe foi acrescentada por Domenico Schmidt, que se apresenta, em nota de rodapé, como "Convertido pela graça de Deus à Igreja Católica, tradutor e revisor no Centro Dom Bosco e professor particular de latim e inglês" (2020, p. 15).

O autor da apresentação, provido por certo das melhores intenções apologéticas, associa o conhecimento do latim a uma defesa da cristandade e da civilização ocidental. Deixamos de lado as convicções religiosas, pois cada qual é livre para pensar e apregoar o que bem desejar. Mas é preocupante a apologia do latim sob uma perspectiva etnocêntrica: a defesa do que seriam os ideais ocidentais vistos como forma superior de civilização, um tópos que encontraremos em certos defensores dos Estudos Clássicos que professam ideologia de (extrema) direita. Leia-se:

O vínculo formado entre o Evangelho e a Civilização Ocidental [as maiúsculas são sintomáticas...] é tamanho que talvez possamos dizer que não há conversão de povo bárbaro sem ao menos algum grau de ocidentalização. Não há Cristandade possível com o sistema jurídico maometano, não há família católica com as comunidades de ocas indígenas, não há teologia possível dentro da metafísica budista. [...] É dever nosso, como católicos e como latinistas, defender tal Civilização pela salvação das almas e para a maior glória de Deus. Como alternativa ao Ocidente existem somente a barbárie pagãa a idolatria e a perversão moral e social [veremos formulação muito parecida mais abaixo, em citação de Olavo de Carvalho]. Não nos surpreende a exaltação dos "intelectuais" na Academia às doutrinas orientais e tudo o mais que venha em antítese ao que há de bom, belo e justo e verdadeiro, etc. (p. 17)

As palavras falam por si para qualquer leitor menos imbuído de uma adoração a certa noção de ocidente que caracteriza como negativo, "bárbaro", tudo o que não é ocidental. E no pacote das maravilhas do ocidente estaria o estudo do latim.

Não é de hoje que, em artigos e palestras, chamamos a atenção para a apropriação que intelectuais e jovens conservadores fazem da herança clássica, deixando entrever uma construção muito própria do que seria a Antiguidade, associada a ideias de disciplina, moral e cívica etc., por vezes em oposição ao que seria barbárie pura e simples. Como esse tipo de apropriação é feita pela (extrema) direita, tudo o que se identifica como bandeiras de esquerda é mencionado como a antípoda de tais ideais.

Olavo de Carvalho, em entrevista ao jornal Folha de São Paulo, publicada em 23 de setembro de 2006, afirmava o ideário direitista e incluía nele a "cultura clássica": 
[...] direita, conservadorismo genuíno, é a síntese inseparável dos seguintes elementos: liberdade de mercado, valores judaico-cristãos, cultura clássica, democracia parlamentar e império das leis. O resto é comunismo, fascismo, nazismo, anarquismo, tecnocracia, socialismo light, o museu inteiro do besteirol político.

Diogo Mainardi, numa crônica para a revista $V$ eja (de 8 de outubro de 2008$)^{2}$ em que atacava a reforma ortográfica, "propugnando", ironicamente, a abolição do alfabeto, dizia, pensando na eliminação das letras que, sem representarem mais som algum, subsistem no português escrito de Portugal:

Eu entendo perfeitamente o empenho dos brasileiros em deslatinizar a língua escrita. De certo modo, o latim representa tudo o que rejeitamos: os valores morais, o rigor poético, o conhecimento científico, o respeito às leis, a simetria das formas, o pensamento filosófico e a harmonia com o passado, o estudo religioso.

Em 2012, a imprensa noticiou que um grupo de jovens conservadores pretendia reviver o antigo partido que foi esteio da ditatura militar no Brasil, o Arena (sigla para Aliança Renovadora Nacional), fundado dois anos depois do golpe militar de 1964:

No programa da nova Arena, constam propostas como a privatização do sistema penitenciário; a abolição de qualquer sistema de cotas raciais, de gênero, ou condições "especiais"; a aprovação da maioridade penal aos 16 anos; o retorno ao currículo escolar de disciplinas como moral e cívica e latim; a retomada do controle de estatais fundamentais à proteção da nação; e o reaparelhamento das Forças Armadas (O Globo, 15/11/2012). ${ }^{3}$

De novo, associa-se "moral e cívica" ao estudo de latim, que integra um ideário de direita, ou extrema-direita, já que se trata de reviver um partido originalmente aliado de um projeto ditatorial.

Nos Estados Unidos, o professor Dan-el Padilla Peralta, nascido na República Dominicana, mas radicado naquele país e professor renomado na Universidade de Princeton, vem denunciando o aspecto colonialista e racista dos Estudos Clássicos. Conforme reportagem do The New York Times,

For several years, he has been speaking openly about the harm caused by practitioners of classics in the two millenniums since antiquity: the classical justifications of slavery, race science, colonialism, Nazism

\footnotetext{
${ }^{2}$ Disponível em http://www.observatoriodaimprensa.com.br/entre-aspas/veja-36750. Acesso em: 15 mar. 2021.

${ }^{3}$ Disponível em: http://g1.globo.com/rs/rio-grande-do-sul/noticia/2012/11/jovens-estudantestentam-refundar-partido-simbolo-da-ditadura-militar.html. Acesso em: 15 mar. 2021.
} 
and other 20th-century fascisms. Classics was a discipline around which the modern Western university grew, and Padilla believes that it has sown racism through the entirety of higher education. ${ }^{4}$

Não podemos aqui relatar as reações várias dos classicistas a tal dossiê de acusação contra os Estudos Clássicos, apenas ressaltamos que sua apropriação por certa (extrema) direita, inclusive pelos supremacistas brancos dos Estados Unidos, é um fato. No Brasil, como vimos, essa apropriação tem-se dado há alguns anos sem que se levantem, ao que saibamos, vozes contraditórias: é como se nós, acadêmicos, sequer déssemos atenção para um fenômeno percebido como marginal. Mas essa associação pode produzir prejuízos concretos para nosso campo de estudos, sobretudo quando jovens conservadores se deixam seduzir por ideias extremistas para cuja defesa invocam, por exemplo, os supostos valores morais dos clássicos. Assim, os Estudos Clássicos acabam associados a tudo o que existe de mais retrógrado e mais etnocêntrico, no limite racista, como diz, em oportuna provocação, o professor de Princeton.

O texto de apresentação da gramática de Ravizza é mais um documento para o dossiê brasileiro de certa apropriação dos Estudos Clássicos de que nós, classicistas, devemos estar conscientes. Pessoalmente, perguntamo-nos como poderíamos indicar a nossos alunos de Latim uma edição (de resto, como dissemos, editorialmente bem feita), que traz em suas primeiras páginas uma ideologia tão danosa à imagem da área?

\footnotetext{
${ }^{4}$ Disponível em https://www.nytimes.com/2021/02/02/magazine/classics-greece-rome-whiteness. html. Acesso em: 15 mar. 2021.
} 